\title{
Disease Mongering in Psychiatry: Fact or Fiction?
}

\author{
Saddichha $\mathrm{S}^{1}$ \\ 'Department of Psychiatry, National Institute of Mental Health \& Neurosciences (NIMHANS), Bangalore, India.
}

\begin{abstract}
Disease mongering starts at the top of recent accusations being hurled at psychiatry. It is used to refer to the attempts by pharmaceutical companies or others who have similar interests, to enlarge the market for a treatment by convincing people that they are sick and need medical intervention. This paper critically analyses the 'for' and 'against' arguments of disease mongering in psychiatric disorders, both new and old, such as Bipolar disorders, attention deficit hyperactivity disorder, Restless legs syndrome, Premenstrual dysphoric disorder, female sexual dysfunction, social phobia, metabolic syndrome and road rage disorder
\end{abstract}

Keywords: disease mongeringpharmaceutical companies, psychiatry.

\section{INTRODUCTION}

If I shop too much, I suffer from compulsive shopping disorder.

If I am shy, I have social phobia.

If I shake my legs while I think, I have restless legs syndrome.

If I am driving too fast to get somewhere, I probably have Road Rage Disorder.

If I am losing hair, I am mostly stressed out and I need anxiolytics.

Psychiatry today stands on the verge of being declared the "discovery of the decade", with rapid advancements being made each day in the understanding of the human brain and consequently, psychiatric disorders. One would only have to take a look at the increasing acceptance by both our professional brethren from other disciplines as well as the general public to know that this is not an exaggeration. Yet, like all good things come handin-glove with a few bad ones, psychiatry has also been recently plagued with several controversies, such as ethics of clinical trials, the "discovery" of antipsychotic induced metabolic syndrome and of accusations of cosmetic psychopharmacology. Disease mongering starts at the top of the queue here.

\section{CONCEPT}

The term "disease mongering" was first described by Lynn Payer in the 1990s and has been subsequently modified to refer to the attempts by pharmaceutical companies or others who have similar interests, to enlarge the market for a treatment by convincing people that they are sick and need medical intervention. What this involves is the creation of so-called new diseases, and then rapid research into it to disseminate information. The problem with these 'new diseases' is
Correspondence:

Dr. Sahoo Saddichho

Department of Psychiatry

National Institute of Mental Health \& Neurosciences

(NIMHANS)

Bangalore, India.

Email: saddichha@gmail.com

Phone: +919886488380 
that the diagnosis of the symptoms could span a broad spectrum of severityfrom nonspecific symptoms and everyday experiences, to profound suffering.

One may argue that knowledge about any disease is good as it helps keep the general public in good health by improving awareness and enabling them to take preemptive action. Unfortunately, it does another thing too- it also helps increase the size of the market by reducing the boundaries between health and sickness so that normal experiences get labeled as pathological, and by expands the definition of disease to include milder and even pre-symptomatic forms. This can be easily discernible in the patterns of spending of the pharmaceutical industry, which spends more money on marketing and advertising than on research and development.

However, there is another side to this story too. The critics of this concept argue that marketing practices in the pharmaceutical industry are similar to those in other industries, all of which emphasise increasing markets for and maximising use of their products. They also say that they are only providing the public with information about treatment options and that actual prescription is a matter between patient and doctor. They therefore complain that is unfair to single them out and label them as "bad". Sometimes, critics have even accused the proponents of disease mongering as being extensions of the Scientology based organizations and antipsychiatry movement in an attempt to discredit psychiatry, neurobiological disorders, and the medications used for treatment.

\section{DISEASE MONGERING IN PSYCHIATRY}

Initially, pharmaceutical companies targeted general consumers with "lifestyle drugs" for cosmetic and sexual enhancements. This has now been broadened to include other areas of medicine, including psychiatry. Marketing campaigns of pharmaceutical companies, which initially focused on cosmetic and sexual enhancements, have recently crossed-over to selling psychotropic drugs. Since most of these drugs have a very wide range of active properties, the interpretation of their 'effects' is also used with a great degree of "wideness" by the marketer. For example, one class of antidepressants, the specific serotonin reuptake inhibitors (SSRIs), is marketed for eight distinct psychiatric conditions, ranging from social anxiety disorder to obsessivecompulsive disorder to a non-existent (at least in textbooks) premenstrual dysphoric disorder.

One can gauge the seriousness of this issue by the content of a recent New York Times article: "For a sizable group of people in their 20's and 30's, deciding on their own what drugs to take-in particular, stimulants, antidepressants and other psychiatric medications - is becoming the norm. Confident of their abilities and often skeptical of psychiatrist's expertise, they choose to rely on their own research and each other's experience in treating problems like depression. A medical degree, in their view, is useful but not essential". The emergence of this potentially dangerous situation demonstrates an increasing expansion of the drug industry into an already accepted mode of thought - that "every minor mood fluctuation," as the article reported, can and should be remedied.

The broad influence of the pharmaceutical industry does not just stop there. This influence now extends to wide domains such as initiating clinical studies or influencing outcomes in research publications, lobbying with governments and regulatory agencies, getting involved in educative programs, advertising and pointof-use promotion, drug distribution among pharmacies and interfering in patients' medicative practices on the pretext of ensuring compliance. Pharmaceutical companies are now engaged in direct advertisements to customers whereby they induce patients to become equal partners with industry and reap huge profits.

\section{COMIMENT}

The negative consequences of disease mongering are only to be seen to be believed. Many of life's normal processes like birth, ageing, sexuality, unhappiness and death have been medicalised. Since simply labeling people with disease can have negative consequences, we are now confronted with a situation of every man/ woman popping a pill everyday to stay away from illness. It's been called the "medicalisation of our society - the pill for every ill." Yet, one fails to understand if this 'panic reaction' is indeed true or a creation of conspiracy theorists. A critical dissection of the 'for' and 'against' arguments is therefore essential.

\section{DISEASE IMONGERING IN BIPOLAR DISORDERS}

Bipolar disorders are one of the most investigated disorders in psychiatry, primarily since there is both a cure as well as prevention for it. Naturally, they have also attracted the most attention by proponents of diseasemongering. An increasing number of epidemiological surveys have noted an increasing prevalence of bipolar disorders. Whether this reflects an unearthing of hitherto hidden disease or an attempt to 'sell' bipolar disorders is yet not clear. The chief criticism in these surveys has been the absence of clearly defined criterion for disability arising due to the illness and the manufacturing of other bipolar types such as bipolar 1, 2, 2.5, 3, 3.5, 4,5 , and 6 popularly called as the 'bipolar spectrum disorders'. Such an attempt to dilute the concept of bipolar disorders may mean that actual patients may 
Saddichha et al. Disease Mongering in Psychiatry: Fact or Fiction?

suffer and put a question mark on the validity of the diagnosis, although it is entirely implausible that mania and melancholia were also manufactured by Esquirol and Kraepelin.

A similar argument has been made for treatments of bipolar disorders. Statements such as "bipolar disorder is often a lifelong illness needing lifelong treatment; symptoms come and go, but the illness stays; people feel better because the medication is working; almost everyone who stops taking the medication will get ill again and the more episodes you have, the more difficult they are to treat" and that "medicines are crucially important in the treatment of bipolar disorders" only serve to perpetuate the accusation of diseasemongering. Similarly, claiming that 'studies over the past twenty years have shown beyond the shadow of doubt that people who receive the appropriate drugs are better off in the long term than those who receive no medicine' are a little hard to digest. Every clinician involved in the treatment of psychiatric illnesses knows that these are difficult statements to make, especially when the risk-benefit ration of psychotropic drugs is not that good. There is also evidence to show that psychotropic medications have done little to change the prevalence of admissions in bipolar disorders and that there is a higher rate of suicide in bipolar patients on psychotropic medications than on placebo.

Many websites are being added every day to "educate" patients on bipolar disorders. A simple search on bipolar disorders on Google brings up http://www. bipolarawareness.com/, http://www.bipolarhelpcenter. com/, and http://www.bipolar.about.com/.Websites by health professionals dealing with bipolar illness are few and far in between. This attempt to 'educate' patients would certainly raise a few eyebrows, since the top websites are sponsored by major pharmaceutical companies. However, it is also a fact that patient education always does not amount to disease mongering. For example, http://www.psycheducation. org is a website that gives information about bipolar disorders, earning it the Moffic Award for Ethical Practice in Community Psychiatry. One would have to conclude that, although not all research is 'influenced', it is entirely possible that over-diagnosis is carried out often influenced by the pharmaceutical industry.

Currently, there is serious criticism of the trend of diagnosing bipolar disorders in children. Since, there are no established criteria to do so, it is difficult to believe the increasing prevalence from $1 \%$ to $32 \%$. Today, even everyday behavioral difficulties are now better seen in terms of a disorder, and children as young as two years are being diagnosed with bipolar disorder.The fashion to diagnose bipolar disorders in children has now reached feverish proportions with even Time magazine, in August 2002, featuring nineyear-old lan Palmer and a cover title called 'Young and Bipolar'. Although pediatric bipolar disorder is a reality, serious research into this debilitating condition has been unfortunately hampered by statements of some experts who have even gone to the extent of saying that that the first signs of bipolar disorder may be patterns of over-activity in-utero.

\section{COMMENT}

Although most of the criticism of bipolar disorders is unwarranted, there is a need to exercise serious restraint among researchers. There have been instances when articles have been "ghostwritten" for wellrespected medical researchers in prestigious journals, and even where some of them have articles authored by (prominent) people who stand to directly benefit from promoting certain treatment regimens in the articles. When these same articles are thrust in our (doctors') faces by visiting marketing representatives, it makes it difficult to reject such claims. It makes the situation so complex that we are no longer aware of what research to trust and what not to. We must understand that our basic emotions-love, hate, happiness, sadness, anger etc. cannot be medicalised. The other extreme that has been depicted in the movie "Equilibrium," where all mood fluctuations are controlled by pills, is too horrifying to be even imagined.

\section{DISEASE MONGERING IN ADHD}

Attention deficit hyperactivity disorder is a serious problem afflicting $5.29 \%$ of children and adolescents around the world with persistence of symptoms into adulthood noted to be in the range of $4-66 \%$. Although there are well defined diagnostic criteria laid down by both DSM IV and ICD 10, yet the danger of overdiagnosis is constantly present and currently, this runs a close second to bipolar disorders as the most diagnosed condition.

The DSM-IV diagnostic criterion permits teachers to play an important role in diagnosis through the use of specialised assessment instruments such as the Conners Teacher's Rating Scale. In a study of 491 physicians in Washington, D. C., almost half of the diagnoses of ADHD in their patients had been suggested first by teachers, an argument advance by critics that teachers are now "disease-spotters," who engage in disease-spotting [38]. Websites funded by pharmaceutical companies are big sources of information which "educates" teachers on the diagnosis and management of ADHD. Educational programs are also held to publicize ADHD through funding from companies. And advertisements for atmoxetine, the first approved medication for adult ADHD, which suggests that consumers get checked 
out by their physician, so that "they stay focused and can get things done at work and at home," certainly don't help.

Similar criticism has been leveled at adult ADHD. The biggest criticism has been that ADHD is just a set of normal behavioral variations, with no neurological basis for the same. The above author has repeatedly said that the concept of ADHD is a fraud with psychiatry making "Patients" of normal people and has testified widely about the absence of proof of causation of ADHD. Unfortunately, there is also a serious dearth of epidemiological research on ADHD. Clinicians treating $A D H D$ also know that this is a real condition that impairs and disables people, and people suffering from this condition are thankful they were "diagnosed, treated and had their attention span restored to almost normal.".

\section{COMMENT}

ADHD is a serious condition that impairs and disables severely if untreated. To say that this is a complete figment of imagination is pushing it too far. Since it is a condition that has only recently been recognized, it is but natural that there will be both false and true studies. Eventually, it will be as recognized and accepted as AIDS, a condition which drew similar accusations decades ago when it was first discovered. Until such a time, it is imperative that people with this disorder are not over-treated with psychostimulants and that they are subjected to psychological interventions too.

\section{DISEASE MONGERING IN PREMENSTRUAL DYSPHORIC DYSFUNCTION (PIMDD)}

The biggest support of the argument that new diseases are being created everyday comes from the diagnosis of PMDD or Premenstrual Dysphoric disorder which does not exist in more than half the world, was earlier considered as part of normal menstrual cycle and is not recognized by the ICD 10 . Yet the US FDA has already approved even a treatment regimen for the same effectively accepting the existence of the condition. One wonders what the hurry was in approving treatment for a condition that officially does not even 'exist'.

It is a fascinating story that details the discovery of the disease. Word has is that the owners of a certain brand of fluoxetine were about to lose their patent. They then funded a meeting of researchers and FDA officials where PMDD was 'officially' born and Fluoxetine (in another brand name) was approved as treatment of choice. By then the makers had redesigned and repackaged the same drug and sold it under a different brand name, "the smart drug for smart women" [40]. Similarly Australia, following the lead of FDA has also approved the use of SSRIs for treatment of PMDD but does not cover the costs of treatment under medical insurance. However, the biggest setback for PMDD promoters and a shot in the arm for activists of disease mongering came from the refusal of the European Medicines Evaluation Agency, citing concerns that women "with less severe pre-menstrual symptoms might erroneously receive a diagnosis of PMDD resulting in widespread inappropriate short- and long-term use of fluoxetine". Lilly has stopped marketing the drug in Europe. The debate remains wide open between supporters and those against the validity of the diagnosis of PMDD.

\section{COMMENT}

PMDD may be a disorder that is fully defined in the future, or it may just be a fad like what Chronic Fatigue syndrome has often been accused of. Since the boundaries of this disorder and hence the prevalence is not defined, treatments for this should wait until they undergo rigorous evaluation.

\section{DISEASE MONGERING IN RESTLESS LEGS SYNDROME}

The diagnosis of restless legs syndrome requires the presence of the following four criteria according to a recent report:

An urge to move the legs due to an unpleasant feeling in the legs.

Onset or worsening of symptoms when at rest or not moving around frequently.

Partial or complete relief by movement (e.g., walking) for as long as the movement continues.

Symptoms that occur primarily at night and that can interfere with sleep or rest.

After "awareness" of so-called criteria, one major pharmaceutical company then promoted the illness, beginning with press releases about presentations at the American Academy of Neurology meeting describing the early trial results of using ropinirole (a drug previously approved for Parkinson disease) for the treatment of restless legs [43]. Two months later, the same company issued a new press release entitled "New survey reveals common yet under recognized disorder-restless legs syndrome-is keeping Americans awake at night" about an internally funded and, at the time, unpublished study. In 2005, the US Food and Drug Administration (FDA) approved ropinirole for the treatment of restless legs syndrome which became the first drug approved specifically for this indication. Since then, the campaign to promote restless legs syndrome into the consciousness of doctors and consumers alike" has reached disturbing extents. It has exaggerated 
Saddichha et al. Disease Mongering in Psychiatry: Fact or Fiction?

the prevalence of disease and the need for treatment, and failed to consider the problems of overdiagnosis. Increasing number of articles and research papers published on this topic have only fuelled the epidemic.

Comment: Like PMDD, restless legs syndrome is a disorder that has neither body nor soul. Since there is no empirical scientific evidence available, which is agreeable to all professionals across the board, doctors should tread carefully and consider other possibilities before coming to this diagnosis.

\section{OTHER PSYCHIATRIC DISORDERS:}

Dementia: The use of various drugs to treat dementia, such as anti-cholinesterase inhibitors, have been recently criticized as lacking clinical evidence, since most trials of donepezil, rivastigmine and galantamine have been limited by underpowered studies, poor methodological quality and using invalidated scales or instruments to measure improvement. Most meta-analyses and reviews of treatment benefits of cholinesterase inhibitors in both Alzheimer's, Parkinson's and vascular dementia have found low treatment effect, minimal benefits, biased reporting and mixed and confusing results. This has prompted United Kingdom's National Institute for Health and Clinical Excellence (NICE) guidelines to state that clinical outcome of use of cholinesterase inhibitors is limited and largely inconclusive and not recommending its use. However, in a later change, the updated guidelines state that they may be used for moderate types of Alzheimer's disease. An integrated approach involving both psychosocial and pharmacological strategies individualized for each patient is essential as even a moderate improvement in a patient with dementia may appear ground-breaking for both patient and carer.

Social Phobia: Shyness has a new name-social phobia. Although this disorder exists in reality, the methods by which this diagnosis is being pushed and promoted is deplorable. In Australia, a certain pharmaceutical company claimed that one million Australians suffered from social phobia. The condition was described as "soul destroying" and antidepressants were recommended for treatment. However, such a claim may be part of a wider push to change the common perception of shyness, from a personal difficulty to a psychiatric disorder. Even Pharmaceutical Marketing's practical guide was led to come out and declare that the promotion of social phobia was a positive example of drug marketers attempting to shape medical and public opinion about a disease. Once again, lest the real patients be missed in all this promotion, one needs to be on guard against such blatant use of marketing.
Female sexual dysfunction: Female sexual dysfunction (FSD) was almost created overnight when pharmaceutical companies, sponsored a May 1997 Cape Cod conference, "Sexual Function Assessment in Clinical Trials," bringing together papers and discussion which were published in a special supplement to the International Journal of Impotence Research. After that, there was no stopping the rapid dissemination of information on a disease that did not exist- television programs such as "Oprah"; Web sites, and books and in innumerable women's magazines. Viagra and then a testosterone patch were promoted as treating FSD. Efforts are now on to include this in the official directory of diseases ICD and DSM. Whether the condition exists in reality or is a figment of a marketer's imagination remains to be seen.

Metabolic syndrome: Metabolic syndrome has become the new rage in psychiatry, especially in psychopharmacology. However, this concept has not been viewed as being promoted by drug manufacturers as they only stand to lose with what is being rapidly seen as a detrimental effect of second generation antipsychotics. Research papers on the topic are being published nearly every day including that of this author. However, questions have been raised whether: 1 ) is it indeed a syndrome, particularly as the precise cause is unknown, 2) does it serve a useful purpose, and 3) is it labelling (and medicalising) people unnecessarily? Additionally, an editorial has suggested that recognition of the metabolic syndrome is being largely driven by industry to create new markets. Even as serious researchers, we need to consider the likelihood of a market-driven campaign before jumping in favor of the diagnosis. Ultimately, all we are looking out for is the patient's interest.

Road rage and compulsive shopping have been added to the ever growing list of doubtful diagnoses. Promoted by both media and psychiatrists, these have invited serious concerns whether psychiatry is turning every aspect of human behavior into a disease. Such has been the ridiculousness of disease mongering that when BMJ printed a "news" item that appeared in its April Fool's Day edition 2006, titled "Scientists find new disease: motivational deficiency disorder", people actually thought it was true and started writing in to say they suffered from it.

\section{FINAL CRITIQUE:SUMIMARY}

As doctors, we are often so pressed for time that we take research at face value as do we claims by pharmaceutical representatives. One is reminded of Aristotle, who so rightly observed that "truth could influence only half a score of men in a century, while falsehood and mystery would drag millions by the nose." 
The issue is even more serious in countries like India where pharmaceutical companies offer various gifts to lure and change the prescribing habits of physicians. Drug companies have been known to have leading researchers as consultants, sponsor annual scientific meetings, and fund continuing medical education (CME) programmes. Medical representatives are allowed free, unrestricted access to doctors and medical conferences are now strongly dominated by the industry. Psychiatry, although not the top priority for most pharmaceutical companies, has started to be "recognized" as a potential field of play. Even though we may argue that there may be no way out of this, we as doctors can do our bit.

Doctors should develop the capacity for critical analysis of research reports and should avoid being misled by biased presentation and interpretation of data. Journal articles, although highly valuable sources of information should not be depended on as the only source. Such critical appraisal skills should be made part of the undergraduate medical course along with prescribing skills. The economics of each drug should be acquired and remembered while prescribing. Doctors should be more careful while attending CME programmes and conferences which are sponsored by the industry.

Disease mongering is neither pure black nor white. Unfortunately, the concept of disease is also a 'grey zone', with inadequate definition of boundaries. There will always be "normal" people who will want treatment and "sick" people who will refuse it. A holistic approach to the patient and patient care is therefore required while deciding treatment strategies.

\section{REFERENCES}

1. Reaven GM. Banting Lecture. Role of insulin resistance in human disease. Diabetes. 1988;37(12):1595-607.

2. Sussman N. General principles of psychopharmacology. In: Sadock BJ, Sadock VA, editors. Kaplan and Sadock's comprehensive textbook of psychiatry. 8th ed. USA: LWW; 2005. p.2676-99.

3. Payer L. Disease mongers: How doctors, drug companies, and insurers are making you feel sick. New York: Wiley and Sons; 1992. p.292.

4. Moynihan R, Cassels A. Selling sickness. How the world's biggest pharmaceutical companies are turning us all into patients. New York: Nation Books; 2005. p.254.

5. Moynihan R, Henry D. The fight against disease mongering: Generating knowledge for action. PLoS Med. 2006;3(4):e191.

6. Angell M. Over and above: Excess in the pharmaceutical industry. CMAJ. 2004;171:1451.

7. Wolinsky H. Disease mongering and drug marketing. EMBO reports. 2005;6(7):612-4. doi:10.1038/sj.embor.7400476

8. Disease mongering. Available at http://en.wikipedia.org/ wiki/Disease_mongering. Retrieved on 22 July 2007.

9. Lal P. Beauty queens and fairness creams. Pop Matters. (December 18, 2003). Available: http//www.popmatters.com/ columns/lal/031218.shtml. Accessed 26 May 2007

10. Chadha M. Indian men go tall, fair and handsome. BBC News. (November 2, 2005) Available: http $/ /$ news.bbc.co.uk/go/pr/ fr/-/2/hi/south_asia/4396122.stm. Accessed 26 May 2007

11. Lexchin J. Bigger and better: How Pfizer redefined erectile dysfunction. PLoS Med. 2006;3:e132 DOI: 10.1371/journal. pmed.0030132

12. Tiefer L. Female sexual dysfunction: A case study of disease mongering and activist resistance. PLoS Med. 2006;3:e178. DOI: 10.1371/journal.pmed.0030178

13. Harmon A. Young, assured and playing pharmacist to friends. New York Times. (Nov 16, 2005). Available at http://www.

nytimes.com/2005/11/16/health/16patient.html. Accessed 16 March 2007

14. Applbaum K. Pharmaceutical marketing and the invention of the medical consumer. PLoS Med. 2006;3(4):e189. doi:10.1371/ journal.pmed.0030189

15. Haynes R, Sackett D, Taylor D, Gibson E, Johnson A. Increased absenteeism from work after detection and labeling of hypertensive patients. N Engl J Med. 1978;299:741-4.

16. Healy D. The Latest Mania: Selling Bipolar disorder. PLoS Med. 2006;3(4):e185. doi:10.1371/journal.pmed.0030185.

17. Healy D. Author's reply: The best hysterias. PLoS Med. 2006;3(7):e320. DOI: 10.1371/journal.pmed.0030320

18. Ghaemi SN. The newest mania: Seeing disease mongering everywhere. PLoS Med. 2006;3(7):e319. DOI: 10.1371/journal. pmed.0030319

19. Zyprexa patient booklet: Manic-Depressive Fellowship. (2004) Staying well with bipolar disorder. Relapse Prevention Booklet. London: Produced in Association with the ManicDepressive Fellowship Sponsored by Eli Lilly and Company.P. 17

20. De-Hert M, Thys E, Magiels G, Wyckaert S. Anything or nothing. Self-guide for people with bipolar disorder. Commentary by P. Grof. Antwerp: Uitgeverij Houtekiet. 2005;35.

21. Joukamaa M, Heliovaara M, Knekt P, Aromaa A, Raitasalo R. Schizophrenia, neuroleptic medication and mortality. Br J Psychiatry. 2006;188:122-7.

22. Healy D. Neuroleptics and mortality: A 50-year cycle: Invited commentary on schizophrenia, neuroleptic medication and mortality. Br J Psychiatry. 2006;188:128.

23. Brown S, Inskip H, Barraclough B. Causes of the excess mortality of schizophrenia. Br J Psychiatry. 2000;177:212-7.

24. Osby U, Correia N, Brandt L, et al. Mortality and causes of death in schizophrenia in Stockholm County, Sweden. Schizophr Res. 2001;45:21-8. 
25. Harris M, Chandran S, Chakroborty N, Healy D. The impact of mood stabilizers on bipolar disorder: the 1890s and 1990s compared. Hist Psychiatry. 2005;16:423-34.

26. Storosum JG, Wohlfarth T, Gispen de Wied CC, Linszen DH, Gersons BP, et al. Suicide risk in placebo controlled trials of treatment for acute manic episode and prevention of manicdepressive episode. Am J Psychiatry. 2005;162:799-802.

27. Phelps J. Confessions of a disease monger. PLoS Med. 2006;3(7):e314. DOI: 10.1371/journal.pmed.0030314.

28. Harris J. The increased diagnosis of juvenile "bipolar disorder," what are we treating? Psychiatr Serv. 2005;56:52931.

29. Findling RL, Kowatch RA, Post RM. A handbook for clinicians. London: Martin Dunitz; 2003.

30. Isaac G. Bipolar not ADHD. Unrecognized epidemic of manicdepressive illness in children. Lincoln (Nebraska): Writers Club Press. 2001.

31. Brooks K. Families with mentally ill children confront health care shortcomings, undeserved stigma of "bad parenting." Fort Worth Star-Telegram: 1, (July 19, 2000)

32. Papolos D, Papolos J. The bipolar child. New York: Random House; 2000. p.416.

33. Burton B, Rowell A. Disease mongering. Centre for Media and Democracy. Available at http://www.prwatch.org/ epublish/1/32. Accessed June 29, 2007.

34. Equilibrium. Internet Movie Database (2002). Available at http://www.imdb.com/title/tt0238380. Accessed Feb 6, 2008.

35. Polanczyk G, Rohde LA. Epidemiology of attention-deficit/ hyperactivity disorder across the lifespan. Curr Opin Psychiatry. 2007;20(4):386-92.

36. Simon V, Czobor P, Balint S, Meszaros A, Murai Z, Bitter I. detailed review of epidemiologic studies on adult attention deficit/hyperactivity disorder (ADHD). Psychiatr Hung. 2007;22(1):4-19.

37. Conners CK. Manual for the Conners' Rating Scales - Revised. North Tonawanda (New York): Multi-Health Systems; 1997.

38. Phillips CB. Medicine goes to school: teachers as sickness brokers for ADHD. PLoS Med. 2006;3(4):e182. doi:10.1371/ journal.pmed.0030182

39. Baughman $F$. There is no such thing as a psychiatric disorder/ disease/chemical imbalance. PLoS Med. 2006;3(7):e318. DOI: 10.1371/journal.pmed.0030318.

40. Moynihan R, Cassels A. Selling sickness: How the worlds biggest pharmaceutical companies are turning us all into patients. New York: Nation Books; 2005. p.99-118.

41. Barbara Mintzes. Disease mongering in drug promotion: do governments havea regulatory role? PLoSMed. 2006;3(4):e198. DOI: 10.1371/journal.pmed.0030198

42. Reuters. Glaxo drug for restless legs syndrome is approved. The New York Times (May 6, 2005); Sect C: 3

43. Woloshin S, Schwartz LM. Giving legs to restless legs: a case study of how the media helps make people sick. PLoS Med. 2006;3(4): e170. doi:10.1371/journal.pmed.0030170
44. Rundle RL. Motion sickness: Restless legs syndrome has long been misdiagnosed and misunderstood; that's about to change. The Wall Street Journal. 2005;Sect R:5

45. Allen R, Walters A, Montplaisir J, Hening W, Myers A. Restless legs syndrome prevalence and impact: REST general population study. Arch Intern Med. 2005;165:1286-92.

46. Groves R, Fowler F, Couper M, Lepkowski J, Singer E. Survey methodology. Hoboken (New Jersey): John Wiley and Sons; 2004. p.448.

47. Lantin B. No sleep for those with restless legs. The Daily Telegraph (December 1, 2004). Available at http:// www.telegraph.co.uk/health / main.jhtml? xml=/ health/2004/01/12/hrest12.xml. Accessed August 12, 2007.

48. Phillips B, Young T, Finn L, Asher K, Hening WA. Epidemiology of restless legs symptoms in adults. Arch Intern Med. 2000;160:2137-41.

49. Maggini M, Vanacore N, Raschetti R. Cholinesterase inhibitors: drugs looking for a disease? PLoS Med. 2006;3(4):e140 doi: 10.1371/ journal.pmed.0030140

50. Lanctôt KL, Herrmann N, Yau KK, Khan LR, Liu BA. Efficacy and safety of cholinesterase inhibitors in Alzheimer's disease: A meta-analysis. CMAJ. 2003;169:557-64.

51. Kaduszkiewicz H, Zimmermann T, Beck-Bornholdt HP, van den Bussche $\mathrm{H}$. Cholinesterase inhibitors for patients with Alzheimer's disease: Systematic review of randomised clinical trials. BMJ. 2005;331:321-7.

52. Black S. Donepezil in vascular dementia: A viewpoint. Drugs Aging. 2003;20:1137-8.

53. Wild R, Pettit T, Burns A. Cholinesterase inhibitors for dementia with Lewy bodies. Cochrane Database Syst Rev. 2003:CD003672.

54. Saddichha S, Pandey V. Alzheimer's and non-Alzheimer's dementia: a critical review of pharmacological and nonpharmacological strategies. Am J Alzheimers Dis Other Demen. 2008;23(2):150-61.

55. Kmietowicz Z. NICE proposes to withdraw Alzheimer's drugs from NHS. BMJ. 2005;330:495.

56. National Institute for Clinical Excellence (NICE). Alzheimer's disease-Donepezil, rivastigmine, galantamine and memantine[online]. 2006; Available from: URL :http:/ / www. nice.org.uk/page.aspx?o=288826

57. Moynihan R, Heath I, Henry D. Selling sickness: the pharmaceutical industry and disease mongering. BMJ. 2002;324:886-91.

58. Cook J. Practical guide to medical education. Pharmaceutical Marketing. 2001;6:1422.

59. Leonore Tiefer. Female sexual dysfunction: A case study of disease mongering and activist resistance. PLoS Med. 2006;3(4):e178. doi: 10.1371/journal.pmed.0030178

60. Moynihan R. The marketing of a disease: female sexual dysfunction. BMJ. 2005;330;192-4.

61. Saddichha S, Manjunatha N, Ameen S, Akhtar S. Metabolic syndrome in first episode schizophrenia- A randomized 
double-blind controlled, short-term prospective study. Schizophr Res. 2008;101(1-3):266-72.

62. Kahn R, Buse J, Ferrannini E, Stern M. The metabolic syndrome: time for a critical appraisal: joint statement from the American Diabetes Association and the European Association for the Study of Diabetes. Diabetes Care. 2005;28:2289-304.

63. Zimmet $P$, Shaw J, Alberti KG. Preventing type 2 diabetes and the dysmetabolic syndrome in the real world: a realistic view. Diabet Med. 2003;20:693-702.

64. Adams M. Psychiatry and disease mongering: Road Rage Disorder is latest spontaneously "discovered" disease. News Target. [serial online] 2006 jun 13 [cited 2007 aug 19]; Available from: URL:http:/ / www.newstarget.com/z019418.html
65. Douglas J. Psychiatry's latest disease mongering scheme: Compulsive shopping called a disease requiring "treatment". News Target. [serial online] 2006 oct 18 [cited 2007 aug 19]; Available from: URL:http://www.newstarget.com/z020805. html

66. Shankar PR, Dubey AK. Disease mongering and medical doctors. BMJ South Asia. 2006;22:16.

67. Giri BR, Shankar PR. Learning how drug companies promote medicines in Nepal. PLoS Med. 2005;2:e256.

68. Amaral OB. Defining disease in the information age. PLoS Med. 3(7):e317. DOI: 10.1371/journal.pmed.0030317 